\title{
Manganese(Iv) oxamato-catalyzed oxidation of secondary alcohols to ketones by dioxygen and pivalaldehyde
}

\author{
Rafael Ruiz, ${ }^{a}$ Ally Aukauloo, ${ }^{a}$ Yves Journaux, ${ }^{*} \dagger$ Isabel Fernández, ${ }^{b}$ José R. Pedro, ${ }^{* b}$ Antonio L. Roselló, $b$ \\ Beatriz Cervera, ${ }^{c}$ Isabel Castro ${ }^{c}$ and M. Carmen Muñoz ${ }^{d}$ \\ a Laboratoire de Chimie Inorganique, URA 420, CNRS, Université de Paris-Sud, 91405 Orsay, France \\ ${ }^{b}$ Departament de Química Orgànica, Facultat de Química, Universitat de València, 46100 Burjassot, València, Spain \\ c Departament de Química Inorgànica, Facultat de Química, Universitat de València, 46100 Burjassot, València, Spain \\ a Departamento de Física Aplicada, Universidad Politécnica de València, 46071 València, Spain
}

\begin{abstract}
A new manganese(Iv) oxamato complex possessing a bis( $\mu$ oxo)dimanganese core has been synthesized, magnetically and structurally characterized, and found to catalyze the aerobic oxidation of secondary alcohols to ketones with cooxidation of pivalaldehyde to pivalic acid with good yields and high selectivities.
\end{abstract}

Interest in high valent manganese coordination chemistry stems largely from the fundamental role that manganese ion in relatively high oxidation states plays in biological dioxygen activation. ${ }^{1}$ Manganese interacts with dioxygen and its reduced derivatives in a variety of enzymes from mononuclear (manganese superoxide dismutase) and dinuclear (manganese catalase or manganese ribonucleotide reductase) to tetranuclear (water-oxidizing complex in photosystem II), making use of the $\mathrm{Mn}^{\mathrm{II}}, \mathrm{Mn}^{\mathrm{III}}, \mathrm{Mn}^{\mathrm{IV}}$ and, probably, $\mathrm{Mn}^{\mathrm{V}}$ oxidation states. Once it was recognized that the active site in catalase and the wateroxidizing complex contains oxo-bridged dimanganese cores, considerable effort was devoted to obtaining dimeric manganese complexes which could be structural as well as functional models for this class of metalloproteins. ${ }^{2}$ During the last two decades several bis( $\mu$-oxo)dimanganese complexes with different ligand types have been reported, but comparatively scarce are the studies concerning their reactivities and, particularly, their use as oxidation catalysts. ${ }^{3,4}$ In fact, the manganese complex in the water-oxidizing center also exhibits oxidation chemistry in its lower oxidation states. ${ }^{5}$ Here we report the synthesis and physical characterization, $\ddagger$ and the crystal and molecular structure $\S$ of the manganese complex $\left[\mathrm{PPh}_{4}\right]_{4}[\mathrm{Mn}(\text { opba })(\mathrm{O})]_{2} \cdot 4 \mathrm{H}_{2} \mathrm{O} \quad \mathbf{1}$, where opba = $o$-phenylenebis(oxamato) ligand, as well as a preliminary investigation of its catalytic oxidation properties with dioxygen.

The structure of 1 consists of centrosymmetric bis $(\mu$ oxo)dimanganese(IV) complex anions, $\left[\mathrm{Mn}_{2}(\mathrm{opba})_{2}(\mathrm{O})_{2}\right]^{4-}$ (Fig. 1), tetraphenylphosphonium cations and crystallization water molecules. The two crystallographically equivalent manganese atoms adopt a distorted octahedral geometry formed by two amide nitrogen and two carboxylate oxygen atoms from two symmetric related opba ligands $(\mathrm{I}=-x,-y,-z)$, each donating one of its NO donor set from oxamato to each of the manganese atom at cis sites; the coordination sphere of the manganese atoms being completed by two oxygen atoms from the two cis-bridging oxo groups. The short $\mathrm{Mn}-\mathrm{O}(1)$ and $\mathrm{Mn}-$ $\mathrm{O}\left(1^{\mathrm{I}}\right)$ bonds of 1.799(4) and 1.797(4) $\AA$, respectively, and the acute $\mathrm{O}(1)-\mathrm{Mn}-\mathrm{O}\left(1^{\mathrm{I}}\right)$ angle of $85.9(2)^{\circ}$, are entirely consistent with a di( $\mu$-oxo)-bridged manganese(IV) complex. ${ }^{2 b}$ Within the

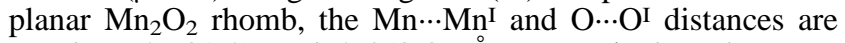
equal to 2.631(2) and 2.453(3) $\AA$, respectively. The most interesting structural feature of $\mathbf{1}$ is, however, the bis-bidentate dinucleating coordination mode of the opba ligand. In fact, the oxamato groups of each opba ligand clamp the two manganese atoms, which are in turn tethered by the phenylene backbone between the amide nitrogen donor set. The phenylene linker forces a twist of the $\mathrm{N}(1)-\mathrm{C}(5)$ and $\mathrm{N}(2)-\mathrm{C}(10)$ bonds by 125.1(5) and $127.0(5)^{\circ}$, respectively, resulting in a dihedral angle between the mean planes of the oxamato groups of the opba ligand of $71.7(2)^{\circ}$. This distortion is also reflected in the Mn-N(amide) bond distances [1.986(5) and 2.006(5) $\AA$ ] which are slightly longer than the $\mathrm{Mn}-\mathrm{O}$ (carboxylate) ones [1.970(4) and 1.965(4) $\AA]$. This unprecedent situation contrasts with that found for the related mononuclear manganese(III) complex with the 4,5-dichloro-opba derivative where the $\mathrm{Mn}-\mathrm{N}$ (amide) and $\mathrm{Mn}-\mathrm{O}$ (carboxylate) bond distances average 1.95 and $1.98 \AA$, respectively. ${ }^{6}$ Within this complex the oxamato ligand adopts an almost planar configuration, and the coordination scheme is the familiar tetradentate $\mathrm{N}_{2} \mathrm{O}_{2}$ one with the ligand occupying the equatorial plane about the manganese atom (trans isomer).

We have investigated the capability of this novel dinuclear manganese(Iv) complex towards oxidative catalytic transformations of various organic substrates by the combined use of dioxygen and an aldehyde as oxidant. ${ }^{7}$ The results obtained for some representative primary and secondary alcohols, both aromatic and aliphatics, are detailed in Table 1. Complex $\mathbf{1}$ selectively catalyzes the oxidation of 1-phenylethanol to the corresponding ketone, acetophenone, by dioxygen plus pivalaldehyde in dichloromethane solution with good yields, i.e.

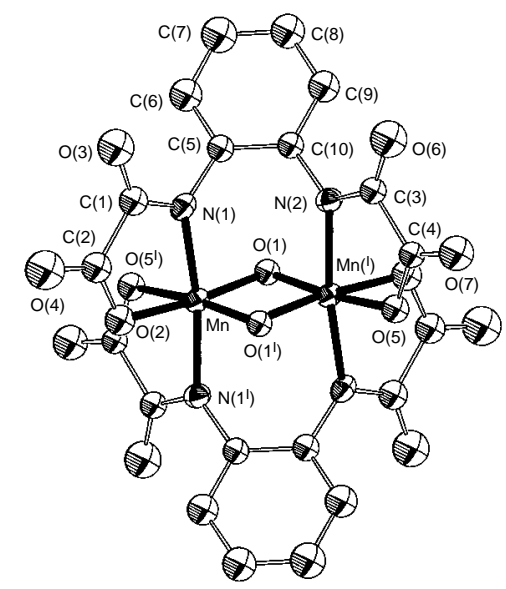

Fig. 1 Perspective view of the anionic dinuclear unit of $\mathbf{1}$ with the atomnumbering scheme (thermal ellipsoids are at the $30 \%$ probability level and hydrogen atoms have been omitted for clarity). Selected bond distances ( $\mathrm{A})$ and angles $\left({ }^{\circ}\right)$ with standard deviations in parentheses: $\mathrm{Mn}-\mathrm{O}(1)$ 1.799(4), $\mathrm{Mn}-\mathrm{O}\left(1^{\mathrm{I}}\right)$ 1.797(4), Mn-O(2) 1.970(4), Mn-O(5) $1.965(4), \mathrm{Mn}-\mathrm{N}(1)$ 1.986(5), Mn-N(2 $2.006(5), \mathrm{Mn}^{\mathrm{I}} \mathrm{Mn}^{\mathrm{I}}$ 2.631(2); O(1)-Mn-O(1) 85.9(2), $\mathrm{O}(1)-\mathrm{Mn}-\mathrm{O}(2)$ 173.0(2), O(1)-Mn-O(5') 93.6(2), O(1)-Mn-N(1) 91.1(2), $\mathrm{O}(1)-\mathrm{Mn}-\mathrm{N}\left(2^{\mathrm{I}}\right) \quad 94.9(2), \quad \mathrm{O}\left(1^{\mathrm{I}}\right)-\mathrm{Mn}-\mathrm{O}(2) \quad 93.8(2), \quad \mathrm{O}\left(1^{\mathrm{I}}\right)-\mathrm{Mn}-\mathrm{O}\left(5^{\mathrm{I}}\right)$ 172.8(2), O(1)-Mn-N(1) 94.5(2), O(1 $\left.1^{\mathrm{I}}\right)-\mathrm{Mn}-\mathrm{N}\left(2^{\mathrm{I}}\right)$ 91.1(2), O(2)-Mn$\mathrm{O}\left(5^{\mathrm{I}}\right)$ 87.6(2), O(2)-Mn-N(1) 81.9(2), O(2)-Mn-N(2 $)$ 92.2(2), O(5 $\left.{ }^{\mathrm{I}}\right)-\mathrm{Mn}-$ $\mathrm{N}(1) 92.7(2), \mathrm{O}\left(5^{\mathrm{I}}\right)-\mathrm{Mn}-\mathrm{N}\left(2^{\mathrm{I}}\right)$ 81.8(2), N(1)-Mn-N(2 $)$ 172.1(2), Mn$\mathrm{O}(1)-\mathrm{Mn}^{\mathrm{I}}$ 94.1(2) (symmetry code: $\mathrm{I}=-x,-y,-z$ ). 
Table 1 Results for the oxidation of alcohols by dioxygen and pivalaldehyde catalyzed by $\mathbf{1}^{a}$

\begin{tabular}{llll}
\hline Entry & Alcohol & $t / \mathrm{h}$ & Yield $(\%)^{b, c}$ \\
\hline 1 & 1-Phenylethanol & 24 & 70 \\
2 & 1-(p-Methoxyphenyl)ethanol & 24 & 75 \\
3 & 1-(p-Bromophenyl)ethanol & 24 & 68 \\
4 & 1-(p-Trifluoromethylphenyl)ethanol & 24 & 65 \\
5 & 1-(p-Nitrophenyl)ethanol & 24 & 60 \\
6 & 4-(tert-Butyl)cyclohexanol & 48 & 50 \\
7 & $p$-Methoxybenzyl alcohol & 12 & $95^{d}$
\end{tabular}

${ }^{a}$ Reactions were carried out at room temp. by adding a $\mathrm{CH}_{2} \mathrm{Cl}_{2}$ solution $(0.2$ $\left.\mathrm{cm}^{3}\right)$ of alcohol $(0.11 \mathrm{mmol})$ to a stirred mixture of metal catalyst $(6.5 \times$ $\left.10^{-3} \mathrm{mmol}\right)$ and pivalaldehyde $(0.33 \mathrm{mmol})$ in $\mathrm{CH}_{2} \mathrm{Cl}_{2}\left(0.2 \mathrm{~cm}^{3}\right)$ under $\mathrm{O}_{2}$ atmosphere. Consumption of alcohol and formation of ketone during the reaction were monitored by TLC. Obtained ketone and unreacted alcohol were separated by flash column chromatography on silica gel. ${ }^{b}$ Yields refer to isolated and pure compounds (column chromatography on silica gel). All compounds exhibited spectral data consistent with their structures. ${ }^{c}$ In the absence of metal catalyst some extension of oxidation was observed. ${ }^{d}$ Reaction product was exclusively $p$-methoxybenzoic acid

$70 \%$ after $24 \mathrm{~h}$ (entry 1), with formation of pivalic acid as a coproduct. Moreover, for the series of para-substituted phenyl derivatives a small but non-negligible electronic effect is observed, as the substrate with the electron-donating methoxy substituent gives a somewhat higher yield of ketone than that with electron-withdrawing substituents such as trifluoromethyl or nitro groups, e.g. $75 \mathrm{vs}$. $60 \%$ after $24 \mathrm{~h}$ (entries 2 and 5, respectively). For all secondary benzyl alcohols, however, ketones were the only oxidation products as confirmed by ${ }^{1} \mathrm{H}$ NMR spectroscopy. Notably, for the oxidation of 4-(tertbutyl)cyclohexanol only 4-(tert-butyl)cyclohexanone was obtained, and no traces were detected of the corresponding Baeyer-Villiger oxidation product, 4-(tert-butyl)caprolactone (entry 6). ${ }^{8}$ This observation suggests that the acylperoxy radicals generated in situ from the auto-oxidation of the aldehyde are not directly involved as potential oxidizing agents. As expected, under the same reaction conditions used for the oxidation of secondary alcohols to ketones, the primary alcohols give mixtures of both the aldehyde and the acid oxidation products in variable amounts depending on the reaction time, as exemplified by $p$-methoxybenzyl alcohol which leads to almost quantitative formation of p-methoxybenzoic acid, i.e. $95 \%$ after $12 \mathrm{~h}$ (entry 7 ).

Although it is premature to discuss the precise role of the metal complex in the catalytic mechanism at the present stage, it is noteworthy that $\mathbf{1}$ alone does not lead to alcohol oxidation under stoichiometric conditions and, consequently, involvement of a bis( $\mu$-oxo)dimanganese(IV) species as the active oxidizing agent can also be ruled out. In a typical experiment, complex $1(0.11 \mathrm{mmol})$ in dichloromethane $\left(20 \mathrm{~cm}^{3}\right)$ does not react with the more reactive substrate 1-( $p$-methoxyphenyl)ethanol $(0.11 \mathrm{mmol})$ even after a period of three days under stirring at room temperature with or without oxygen atmosphere conditions. That being so, manganese(IV)acylperoxo or higher valent metal intermediate species, such as manganese(v)-oxo, derived from the oxidation of the bis $(\mu$ oxo)manganese(IV) dimer by the combination of dioxygen and pivalaldehyde, are considered more likely to be responsible for the oxidation in our system. More interestingly, stable manganese(v)-oxo monomeric complexes with amido-containing ligands analogous to that used herein have been isolated and structurally characterized. ${ }^{9}$ Attempts to isolate these reactive intermediate species using transition metal ions with more accessible high-valent oxidation states such as chromium are in progress.

This work was supported by the DGICYT, Ministerio de Educación y Ciencia (Spain) through projects PB94-0985 and PB94-1002. R. R. and B. C. thank the Ministerio de Educación y Ciencia (Spain) and the Conselleria de Educació i Ciència de la Generalitat Valenciana (Spain) for grants. We would also like to express our gratitude to Professor J. J. Girerd and Dr G. Blondin for fruitful discussions and continuous interest in this work.

\section{Notes and References}

$\dagger$ E-mail: jour@icmo.u-psud.fr

$\$$ Synthesis and selected data for 1 : the diethyl ester derivative of the opba ligand $(1.54 \mathrm{~g}, 5 \mathrm{mmol})$ was dissolved in deoxygenated $\mathrm{MeOH}\left(100 \mathrm{~cm}^{3}\right)$, $\mathrm{NMe}_{4} \mathrm{OH}$ at $25 \%$ in $\mathrm{MeOH}\left(8 \mathrm{~cm}^{3}, 20 \mathrm{mmol}\right)$ was added to the solution and the resulting mixture was stirred at $60{ }^{\circ} \mathrm{C}$ for 15 min under $\mathrm{N}_{2}$. A deoxygenated $\mathrm{MeOH}$ solution $\left(50 \mathrm{~cm}^{3}\right)$ of $\mathrm{Mn}\left(\mathrm{ClO}_{4}\right)_{2} \cdot 6 \mathrm{H}_{2} \mathrm{O}(1.79 \mathrm{~g}, 5$ mmol) was then added dropwise via a dropping funnel under $\mathrm{N}_{2}$, and a gelatinous light yellow precipitate [presumably a $\mathrm{Mn}^{\mathrm{II}}$ complex] rapidly formed, together with the crystalline white precipitate of $\mathrm{NMe}_{4} \mathrm{ClO}_{4}$. Addition of $33 \%$ aq. $\mathrm{H}_{2} \mathrm{O}_{2}\left(1 \mathrm{~cm}^{3}, 10 \mathrm{mmol}\right)$ caused immediate darkening of the solution with concomitant disappearance of the yellow precipitate. The reaction mixture was further stirred at $60{ }^{\circ} \mathrm{C}$ for $30 \mathrm{~min}$ under $\mathrm{N}_{2}$. The dark-brown solution was filtered to eliminate the solid $\mathrm{NMe}_{4} \mathrm{ClO}_{4}$, and reduced to a final volume of $10 \mathrm{~cm}^{3}$ on a rotatory evaporator. The concentrated solution was treated successively with diethyl ether and acetone to give a black solid which was recuperated in warm water $\left(50 \mathrm{~cm}^{3}\right)$. The resulting mixture was filtered to eliminate solid particles (mainly $\left.\mathrm{MnO}_{2}\right)$, and an excess of $\mathrm{PPh}_{4} \mathrm{Cl}(3.75 \mathrm{~g}, 10 \mathrm{mmol})$ dissolved in the minimum amount of water was then added dropwise to the dark-brown solution under gentle warming. Slow evaporation of the filtered solution in air afforded, after a few days, well shaped large prismatic dark-brown crystals of 1 suitable for X-ray analysis which were filtered on paper and airdried $(60 \%)$. Satisfactory chemical analyses obtained (C, H, N, P, Mn). $v_{\max } / \mathrm{cm}^{-1}(\mathrm{KBr}) 3477 \mathrm{vs}(\mathrm{O}-\mathrm{H})$ from $\mathrm{H}_{2} \mathrm{O}, 1672(\mathrm{sh}), 1647 \mathrm{vs}, 1617 \mathrm{vs}$ $(\mathrm{C}=\mathrm{O})$ and $1403 \mathrm{~s}, 1306 \mathrm{~s}(\mathrm{C}-\mathrm{O})$ from opba ligand, and $643 \mathrm{~m}(\mathrm{Mn}-\mathrm{O})$ from $\mathrm{Mn}_{2} \mathrm{O}_{2}$ ring. $\lambda_{\text {max }} / \mathrm{nm} 390\left(\varepsilon / \mathrm{dm}^{3} \mathrm{~mol}^{-1} \mathrm{~cm}^{-1} 10800\right), 440(\mathrm{sh})(7080)$ and $605(1170)(\mathrm{MeCN})$. Variable-temperature magnetic susceptibility (Faraday balance, 80-300 K): $J=-158.0 \mathrm{~cm}^{-1}\left(H=-J S_{1} \cdot S_{2}, S_{1}=S_{2}=\right.$ $3 / 2$ ).

$\S X$-Ray crystal structure analysis: Enraf-Nonius CAD-4 diffractometer, Mo-K $\alpha, \lambda=0.71073 \AA$, graphite monochromator, $293 \mathrm{~K}$. Lorentz and polarization effects but not absorption correction $\left(\mu=3.78 \mathrm{~cm}^{-1}\right)$. Data collection, solution and refinement: $\omega-\theta$, standard Patterson methods with subsequent full-matrix least-squares refinement. SHELX86, SHELX93.10 $\mathrm{C}_{116} \mathrm{H}_{96} \mathrm{Mn}_{2} \mathrm{~N}_{4} \mathrm{O}_{18} \mathrm{P}_{4}$, triclinic, space group $P \overline{1}, \quad a=13.245(3)$, $b=13.964(3), c=14.835(3) \AA, \alpha=73.59(2), \beta=77.98(2)$, $\gamma=84.60(2)^{\circ}, U=2572.6(10) \AA^{3}, Z=2, D_{\mathrm{c}}=1.33 \mathrm{~g} \mathrm{~cm}^{-3}, 1 \leqslant \theta \leqslant 25^{\circ}$, crystal $0.15 \times 0.15 \times 0.10 \mathrm{~mm}$. 6681 reflections measured, 4485 assumed as observed with $I \geqslant 2 \sigma(I)$. Refinement on $F^{2}$ of 651 variables with anisotropic thermal parameters for all non-H atoms gave $R=0.060$ and $R_{\mathrm{w}}=0.150$ with $S=0.936$ (obs. data). CCDC $182 / 809$.

1 V. L. Pecoraro, M. J. Baldwin and A. Gelasco, Chem. Rev., 1994, 94, 807.

2 (a) K. Wieghardt, Angew. Chem., Int. Ed. Engl., 1989, 28, 1153; (b) J. E. McGrady and R. Stranger, J. Am. Chem. Soc., 1997, 119, 8512 and references therein.

3 R. Hage, Recl. Trav. Chim. Pays-Bas, 1996, 115, 385 and references therein; W. Ruttinger and G. C. Dismukes, Chem. Rev., 1997, 97, 1.

4 R. Hage, J. E. Iburg, J. Kerschner, J. H. Koek, E. L. M. Lempers, R. J. Martens, U. S. Racherla, S. W. Russell, T. Swarthoff, M. R. P. Van Vliet, J. B. Warnaar, L. Van der Wolf and B. Krijnen, Nature, 1994, 369 637; C. Zondervan, R. Hage and B. L. Feringa, Chem. Commun., 1997, 419.

5 W. F. Beck, J. Sears, G. W. Brudvig, R. J. Kulawiec and R. H. Crabtree, Tetrahedron, 1989, 45, 4903.

6 M. Fettouhi, L. Ouahab, A. Boukhari, O. Cador, C. Mathoniere and O. Kahn, Inorg. Chem., 1996, 35, 4932.

7 R. Ruiz, M. Triannidis, A. Aukauloo, Y. Journaux, I. Fernández, J. R. Pedro, B. Cervera, I. Castro and M. C. Muñoz, Chem. Commun., 1997, 2283.

8 K. Kaneda, S. Ueno, T. Imanaka, E. Shimotsuma, Y. Nishiyama and Y. Ishii, J. Org. Chem., 1994, 59, 2915.

9 T. J. Collins, R. D. Powell, C. Slebodnick and E. S. Uffelman, J. Am. Chem. Soc., 1990, 112, 899; F. M. McDonnell, N. L. P. Fackler, C. Stern and T. V. O'Halloran, J. Am. Chem. Soc., 1994, 116, 7431.

10 G. M. Sheldrick, SHELX. A Program for Crystal Structure Determination, University of Göttingen, Germany, 1990; G. M. Sheldrick, SHELXL93. Program for the Refinement of Crystal Structures, University of Göttingen, Germany, 1993.

Received in Basel, Switzerland, 3rd February 1998; 8/00930I 